\title{
Besilesomab for imaging inflammation and infection in peripheral bone in adults with suspected osteomyelitis
}

This article was published in the following Dove Press journal:

Reports in Medical Imaging

25 August 2010

Number of times this article has been viewed

\author{
Adriana Blazeski' \\ Kenneth M Kozloff',2 \\ Peter JH Scott ${ }^{3}$ \\ 'Department of Biomedical \\ Engineering, University of Michigan, \\ Ann Arbor, MI, USA; 'Orthopedic \\ Research Laboratories, Department \\ of Orthopedic Surgery, ${ }^{3}$ Department \\ of Radiology, University of Michigan \\ Medical School, Ann Arbor, MI, USA
}

Correspondence: Peter JH Scott Department of Radiology, University of Michigan Medical School,

Ann Arbor, MI, USA

Tel + I 7346151756

Fax +I 7346152557

Email pjhscott@umich.edu

\begin{abstract}
Early and accurate diagnosis of osteomyelitis, an inflammatory process of the bone caused by an infective microorganism, is essential for rapid management of the disease by antimicrobial and/or surgical intervention. Historically, diagnosis has been achieved by histological examination, but, more recently, sophisticated molecular imaging techniques (including computed tomography [CT], magnetic resonance imaging, positron emission tomography, single photon emission CT, scintigraphy) that are increasingly used to support diagnoses made from histological data have been reported. For example, scintigraphy has been used to visualize the inflammatory process in vivo using either radiolabeled leukocytes or radiolabeled antigranulocyte monoclonal antibodies (MAbs). Typically, radiolabeling is achieved using technetium-99m (radioactive half-life $=6.02$ hours), and the most commonly used MAbs are the Fab fragment of the immunoglobulin $(\mathrm{Ig}) \mathrm{G}$ antibody directed against the glycoprotein cross-reactive antigen-90 (sulesomab) and an IgG antibody against normal cross-reactive antigen-95 (BW 250/183, besilesomab [Scintimun $\left.{ }^{\circledR}\right]$ ). The aim of the present review is to discuss use of this latter commercially available MAb, besilesomab, for imaging inflammation in adults with suspected osteomyelitis.
\end{abstract}

Keywords: Scintimun, ${ }^{99 \mathrm{~m}}$ Tc scintigraphy, radiolabeled monoclonal antibodies, BW 250/183, bone infection

\section{Osteomyelitis}

\section{General introduction}

Osteomyelitis, an inflammatory process caused by an infective microorganism and accompanied by bone destruction, has been extensively reviewed in the medical literature. ${ }^{1-6}$ It can occur in a confined portion of the bone or involve multiple regions, including the marrow, cortex, periosteum, and surrounding soft tissue. Osteomyelitis can be categorized based on its pathological origins, the most frequent being a local spread from a contiguous focus of infection occurring after trauma, surgery, the insertion of joint prostheses or from diabetic foot infection (Figure 1). ${ }^{1}$ This form occurs most often in adults and accounts for $80 \%$ of cases. ${ }^{7}$ Osteomyelitis of hematogenous origin, on the other hand, occurs when bone is seeded by bacteria present in blood and is found mostly in prepubertal children and in elderly patients. ${ }^{1}$ Osteomyelitis secondary to vascular insufficiency, in which soft tissue infection in the foot spreads to bone, has also been described in populations with diabetic foot infections. ${ }^{8}$ Beyond characterization as contiguous or hematogenous (based on the source of infection), osteomyelitis is also classified as acute or chronic based on its duration. ${ }^{9}$ Acute osteomyelitis can be detected by histological methods 2 weeks after the onset of the disease, whereas 


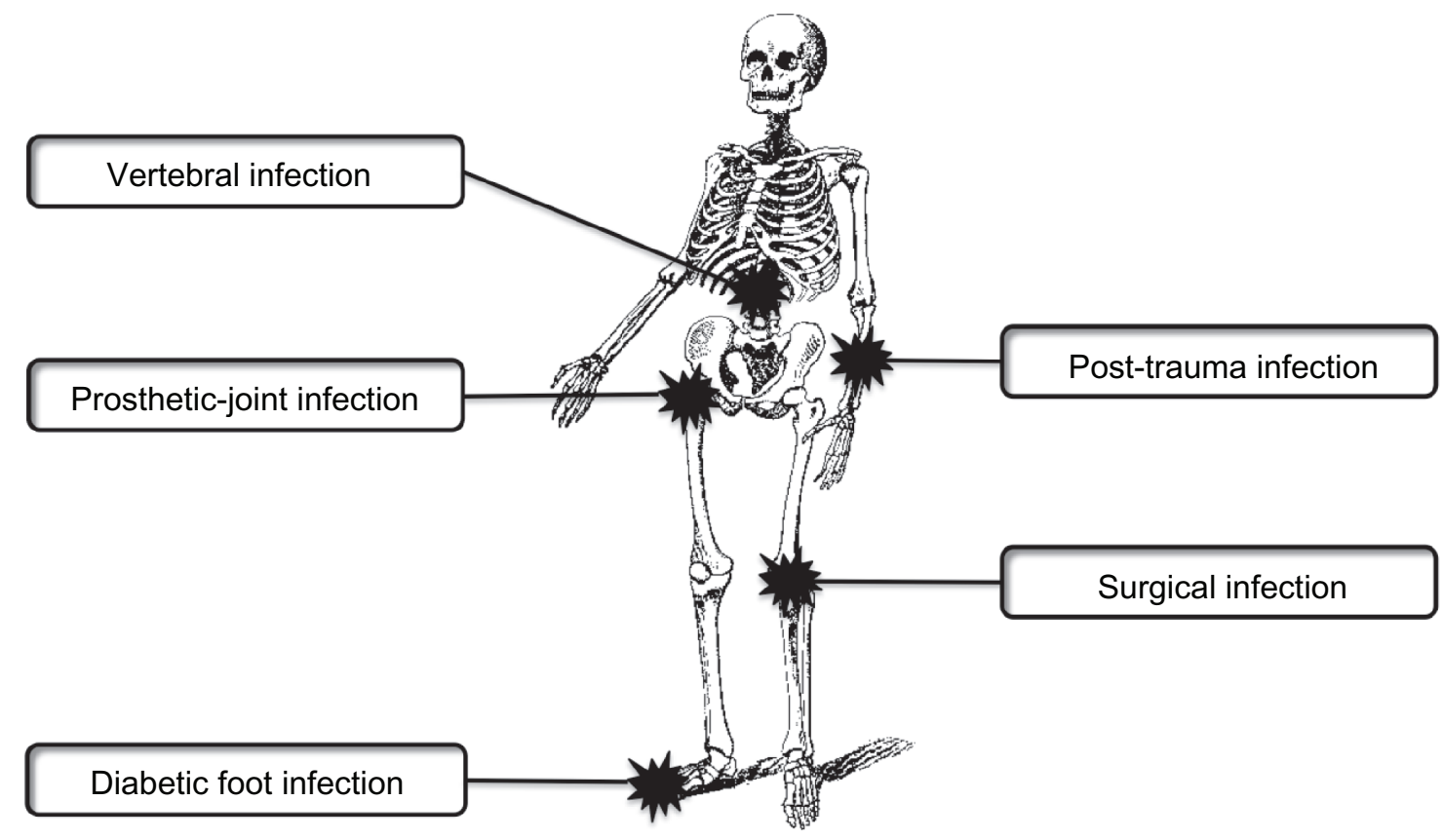

Figure I Common causes of osteomyelitis.

chronic osteomyelitis is long standing, evolving over months or years, and is histologically detectable a few months after disease onset. Other classification systems for osteomyelitis include the Waldvogel and the Cierny-Mader schemes. ${ }^{10,11}$ The latter is used by orthopedic surgeons for treating patients with chronic osteomyelitis and combines considerations of the anatomical stages of the disease and the physiology of the patient. It applies best to long and large bones and is not very useful in classifying the disease in digits, small bones, or the skull.

\section{Development and progression}

Osteomyelitis develops when bacterial contamination and adhesion develop into infection and subsequent chronicity. Pathogenic factors that cause this chronicity can be divided into local and general factors. Local factors include the presence of foreign bodies, bone necrosis, and heavy contamination by devitalized bone fragments from trauma or surgery. Additionally, strains of bacteria may gain a survival advantage from their slow metabolic rates, ability to hide intracellularly, and the presence of a host defect in the presence of an implant. ${ }^{12}$ Biofilm-embedded microorganisms have additional advantages, including the resistance to removal tactics, such as the use of antimicrobial or antifouling agents, shear stress, host phagocytic clearance, and host oxygen radical and protease defenses. Biofilms also have the capability to act as diffusion barriers to slow down the infiltration of some antimicrobial agents and could have the potential to detach and spread under mechanical fluid shear or through genetically mediated detachment processes. ${ }^{13}$ General factors affecting chronicity in patients include diabetes, peripheral vascular disease, obesity, and smoking. ${ }^{12}$

A typical route for osteomyelitis development begins with the production of pus in the medulla leading to the development of an abscess in the marrow space. This swelling presses against the outer wall of bone, compressing the blood vessels in the bone marrow and leading to localized bone death in avascular areas. Resulting reactive hyperemia is associated with increased osteoclastic activity, leading to localized bone loss and osteoporosis. Progression of this process may lead to bone necrosis and fracture of the affected bone (Figure 2). ${ }^{1,2}$

\section{Diagnosis and treatment}

Bone infections are painful and unpleasant for patients and should be treated as early as possible. Acute osteomyelitis responds to treatment with antibiotics alone, although the avascular bone necrosis and sequestrum formation that occur during chronic osteomyelitis may necessitate surgical debridement in addition to antibiotic treatment. ${ }^{14}$ Identification of the causative agent of osteomyelitis is essential for administering effective treatment. For example, Staphylococcus aureus is the main foreign body found in chronic bacterial osteomyelitis, followed by Pseudomonas and Enterobacteriacea. ${ }^{12,15-18}$ However, it should be noted that the successful management of most other infectious diseases by antibiotics has not yet 

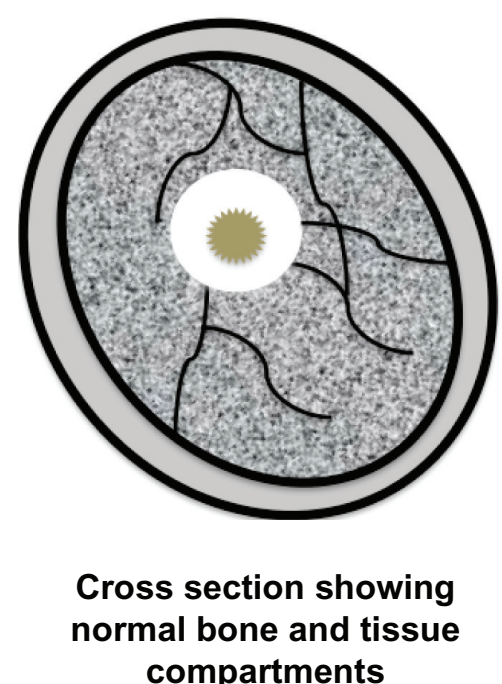
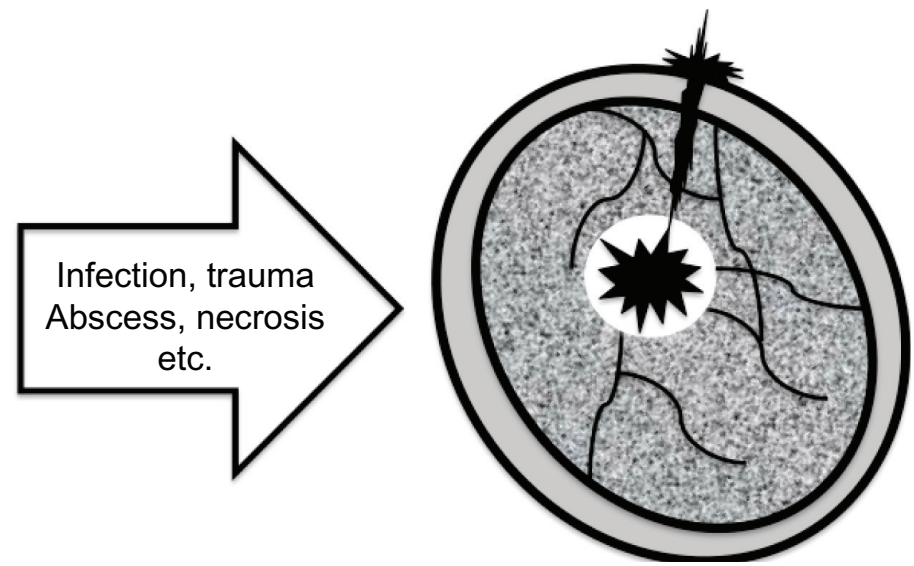

Osteomyelitis

Figure 2 Pathophysiology of osteomyelitis characterized by spread of infection through adjacent soft tissues.

been replicated for osteomyelitis. This is not only due to the unique physiological and anatomical characteristics of bone but also due to difficulties involved in diagnosing osteomyelitis. For example, sometimes osteomyelitis manifests without signs and symptoms. Alternatively, signs and symptoms of osteomyelitis can be difficult to distinguish from other diseases such as neuropathic osteoarthropathy. ${ }^{19}$ Moreover, the frequently concurrent existence of bone and soft tissue abnormalities complicates diagnosis of osteomyelitis, leading to false-positive and false-negative findings. Nevertheless, early and accurate diagnosis is essential for successful management of the disease, and so, much research has been undertaken to develop diagnostic molecular imaging strategies to support histological data. Such developments have been the subject of recent reviews. ${ }^{902-25}$ For example, ultrasound, ${ }^{26,27}$ computed tomography $(\mathrm{CT}),{ }^{21,22,28}$ magnetic resonance imaging (MRI), ${ }^{29-32}$ optical $^{20}$ and nuclear medicine techniques ${ }^{20,23,24,33-37}$ have all been used to improve diagnostic confidence.

\section{Nuclear medicine techniques for diagnosis of osteomyelitis}

A range of nuclear medicine techniques (eg, positron emission tomography [PET], single photon emission CT [SPECT] scans, and scintigraphy) have been developed for imaging inflammation and infection and are increasingly used to diagnose osteomyelitis. ${ }^{20,21,35}$ For example, fluorine-18 fluorodeoxyglucose $\left(\left[{ }^{18} \mathrm{~F}\right] \mathrm{FDG}\right)$, a commercially available PET tracer, has shown promise in imaging chronic osteomyelitis. FDG uptake and metabolism are elevated in leukocytes, granulocytes, and macrophages during inflammatory conditions because of increased cellular expression of glucose transporters. ${ }^{38-40}$ The numerous advantages of FDG-PET imaging include a higher spatial resolution in comparison to conventional nuclear medicine modalities, fast examination time (result available within 1-2 hours after tracer administration), the ability to differentiate between hematopoietic bone marrow and activated white blood cells (WBCs), and potential application to treatment monitoring. ${ }^{41}$ Additionally, the high spatial and contrast resolution of FDG-PET can distinguish soft tissue from osteomyelitis, and the absence of artifacts from metallic implants allows the imaging of patients with suspected infection in hip and knee prostheses. ${ }^{42-44}$ A negative result of PET study essentially rules out osteomyelitis because of its high sensitivity in detecting infection; however, this may lead to increased false-positive results. ${ }^{45,46} \mathrm{~A}$ drawback of FDG-PET is the lack of anatomic landmarks, which may make it difficult to assign lesions to a particular structure. Integrated PET-CT scans can be used for functional-morphologic correlation. ${ }^{39}$

The reported sensitivity and specificity for PET diagnosis of osteomyelitis range from $95 \%$ to $100 \%$ and $86 \%$ to $95 \%$, respectively. ${ }^{46,47}$ The accuracy of FDG-PET in evaluating prosthetic joint infections, however, is higher in hip prostheses than in knee prostheses, perhaps because attenuation correction in imaging knee prostheses can introduce artifacts that lead to false-positive results. ${ }^{48}$ Reported values for sensitivity, specificity, and accuracy of FDG-PET imaging for detecting infections are $90 \%, 89.3 \%$, and $89.5 \%$ for hip prostheses and $90.9 \%, 72.0 \%$, and $77.8 \%$ for knee prostheses, respectively. ${ }^{49}$ 
Scintigraphy has also been used extensively to image inflammation and infection. For example, in cases looking for peripheral osteomyelitis, triple scintigraphy using technetium-99m ( $\left.{ }^{99 \mathrm{~m}} \mathrm{Tc}\right)$-radiolabeled diphosphonates has historically shown good success in detecting the upregulated bone turnover associated with the disease. For example, ${ }^{99 m} \mathrm{Tc}-m e t h y l e n e$ diphosphonate ([99m $\left.\left.\mathrm{Tc}\right] \mathrm{MDP}\right)$ binds to the hydroxyapatite bone crystal, and therefore, signals depend on both blood flow and rates of bone turnover. ${ }^{50}$ During triple-phase imaging, positive signs of osteomyelitis are considered through the combined detection of focal hyperfusion immediately following contrast injection, focal hyperemia in the blood pool phase, and focal increases in bone uptake on delayed images. ${ }^{50}$ Furthermore, the bone scan can alleviate image artifacts, which are found by $\mathrm{CT}$ or MRI in patients with existing implants or prostheses. ${ }^{9}$ However, [ ${ }^{99 \mathrm{~m}} \mathrm{Tc}$ ] MDP imaging only denotes regions of active bone turnover and, therefore, cannot discriminate osteomyelitis from other causes of increased local bone remodeling. ${ }^{9}$ Therefore, specificity of this technique decreases in patients with underlying skeleton conditions, which may otherwise induce a positive finding on the bone scan. ${ }^{50}$ Gallium-67 imaging can be used in conjunction with the bone scan to increase accuracy of detection, but the use of multiple isotopes over several days of imaging can be limiting. ${ }^{50}$ Planar scintigraphy can be further improved using 3D SPECT imaging; however, the same caveats regarding specificity still can limit SPECT imaging of [99m Tc]MDP imaging in osteomyelitis. ${ }^{35}$

Inflammation is the body's early response to injury (and infection) and involves delivery of leukocytes to the infected area where they can clear infectious agents and degrade necrotic tissues. Therefore, scintigraphy using ex vivo ${ }^{111}$ In-oxine-radiolabeled leukocytes has been widely used as the gold standard for imaging the inflammation process. . $21,23,37^{2}$ The leukocytes are radiolabeled and reinjected into the patient where they become distributed in the intravascular space. Patients then typically receive their scan 4-24 hours postinjection. This lapse gives time for blood pool activity to decrease and improves image quality. An area of increased activity is indicative of inflammation and infection, and Indium-111-labeled leukocyte ( $\left.{ }^{111} \mathrm{In}-\mathrm{L}\right)$ scintigraphy is the method of choice for localizing osteomyelitis. However, using radiolabeled leukocytes in this capacity also has associated challenges, because there is always the question of whether the radiolabeled cells remain viable and there is also the loss of specificity associated with imaging a system as complicated as the leukocyte response to inflammation. Moreover, ex vivo labeling entails cumbersome isolation or reinjection of the cells, and this also involves significant radiation exposure and increased risk of infection to both the patient and the staff. ${ }^{21,23,51}$ Therefore, alternative strategies have been developed, including the use of radiolabeled nanocolloids and introduction of radiolabeled antigranulocyte monoclonal antibodies (MAbs), with the aim of addressing some of these issues.

Imaging bone inflammation with ${ }^{99 \mathrm{~m}} \mathrm{Tc}$-labeled nanocolloids ( ${ }^{99 \mathrm{~m}} \mathrm{Tc}-\mathrm{NCs}$ ) offers several advantages over ${ }^{111} \mathrm{In}$-L scintigraphy, including lower radiation doses, ease of handling, and shorter preparation times. Biodistribution studies of ${ }^{99 \mathrm{~m}} \mathrm{Tc}-\mathrm{NCs}$ in the rat have found that the blood activity in bone marrow imaging decreases from $14.5 \%$ at 30 minutes, $12.5 \%$ at 1 hour, and $12.4 \%$ at 3 hours, with $54.5 \%$ renal excretion after 24 hours. ${ }^{52}$ In a study comparing three human albumin colloids and one antimony sulfide colloid, the nanometersized albumin-based colloid labeled with ${ }^{99 \mathrm{~m}} \mathrm{Tc}-\mathrm{Nanocoll}{ }^{\circledR}$ (Nycomed Amersham Sorin S.R.L, Saluggia, Italy) had the highest bone marrow or spleen quotient and bone marrow or background quotient in patient scans. ${ }^{53}$ Flivik et al ${ }^{54}$ found that ${ }^{99 \mathrm{~m}} \mathrm{Tc}-\mathrm{NC}$ scintigraphy with this radiopharmaceutical is equivalent to ${ }^{111} \mathrm{In}$-L scintigraphy with regards to sensitivity, specificity, and accuracy. This study demonstrated a sensitivity of $75 \%$ with ${ }^{111} \mathrm{In}$-Ls and $94 \%$ with ${ }^{99 \mathrm{~m}} \mathrm{Tc}-\mathrm{NCs}$. Specificity of $90 \%$ was demonstrated with ${ }^{111}$ In-Ls and $84 \%$ with ${ }^{99 \mathrm{~m}} \mathrm{Tc}-\mathrm{NCs}$, whereas diagnostic accuracy was $85 \%$ and $87 \%$, respectively. When patients with slightly increased activity were regarded as being negative, the specificity increased to nearly $100 \% .^{54}$ This is in agreement with a study by Papos et al, ${ }^{55}$ which suggests both ${ }^{99 \mathrm{~m}} \mathrm{Tc}-\mathrm{NC}$ and ${ }^{99 m} \mathrm{Tc}$-hexamethyl propylene amine oxime - labeled leukocyte scanning were of similar value for the detection of chronic posttraumatic osteomyelitis. However, leukocyte scintigraphy seemed to characterize the grade of inflammation better than did nanocolloid scintigraphy, with good correlation between the leukocyte scanning data and laboratory and bacteriologic data. Another comparative study found nanocolloid and IgG scans have a similar degree of sensitivity (95\%) and specificity $(100 \%)$ in the detection of focal inflammatory processes but are nonspecific in detecting an infective focus. ${ }^{56}$ On the other hand, Ooi et al ${ }^{57}$ suggest that ${ }^{99 \mathrm{~m}} \mathrm{Tc}-\mathrm{NC}$ cannot replace ${ }^{111} \mathrm{In}$-Ls in the diagnosis of orthopedic infections. In a comparative study involving 19 patients with a high clinical suspicion of infection, the sensitivity was $75 \%$ in both methods, and specificities were $79 \%$ and $60 \%$ for ${ }^{111} \mathrm{In}-\mathrm{Ls}$ and ${ }^{99 \mathrm{~m}} \mathrm{Tc}-\mathrm{NC}$, respectively. Additionally, the positive predictive value was $33 \%$ with ${ }^{99 \mathrm{~m}} \mathrm{Tc}-\mathrm{NC}$ and $50 \%$ with ${ }^{111}$ In-Ls, with three false positives with ${ }^{111}$ In-Ls scanning and 6 with ${ }^{99 \mathrm{~m}} \mathrm{Tc}-\mathrm{NC}$ scanning. ${ }^{57} \mathrm{It}$ has been suggested that 
false positives in nanocolloid scans are due to the suspected localizing mechanism. It is thought that the nanometer-sized particles leak out from the vascular endothelium and basement membrane and enter into the extravascular space and may be taken up into the reticuloendothelial system. In this way, the inflammatory process accounts for the localization of nanocolloid lesions, regardless of the disease etiology. ${ }^{56,58}$

The introduction of radiolabeled MAbs was a step forward in osteomyelitis detection, and this area of research has been the subject of a number of review articles. ${ }^{23,24}$ The most commonly used MAbs are the Fab fragment of the immunoglobulin (Ig)G antibody directed against the glycoprotein cross-reactive antigen-90 (sulesomab) and an IgG antibody against normal cross-reactive antigen-95 (NCA-95; BW 250/183, besilesomab [Scintimun ${ }^{\circledR}$; IBA Molecular Imaging, Dulles, JA]). As besilesomab has marketing approval in Europe ${ }^{59}$ this review will focus upon its use in imaging inflammation and infection to date.

\section{9m Tc-labeled besilesomab General drug information}

Besilesomab (BW 250/183) is a mouse MAb of IgG1 $\kappa$ isotype against NCA-95. The molecular weight of the antibody is $\sim 150 \mathrm{kDa}$, and there are two $\kappa$-light polypeptide chains $(\sim 25 \mathrm{kDa}$ each) and two identical $\gamma 1$-heavy polypeptide chains $(\sim 50 \mathrm{kDa}$ each) that are linked together by disulfide bridges. Besilesomab is radiolabeled with ${ }^{99 \mathrm{~m}} \mathrm{Tc}$ and is marketed as a kit for radiopharmaceutical preparation under the brand name Scintimun. ${ }^{59}$ The kit contains the reduced form of besilesomab (ie, disulfide bridges have been prereduced to the corresponding thiols). ${ }^{99 \mathrm{~m}} \mathrm{Tc}$ (radioactive half-life $\left[t_{1 / 2}\right]=6.02$ hours) is obtained, using a ( ${ }^{99}$ Mo or ${ }^{99 \mathrm{~m}} \mathrm{Tc}$ ) generator, as [ $\left.{ }^{99 \mathrm{~m}} \mathrm{Tc}\right]$ sodium pertechnetate, and this is introduced into the Scintimun kit. The kit contains stannous chloride, which reduces sodium pertechnetate to Tc (IV), and Tc (IV) is then able to bind to the free thiols of the reduced antibody (Figure 3). ${ }^{99 \mathrm{~m}} \mathrm{Tc}$ decays by emission of $140-\mathrm{keV}$ gamma photons to quasistable ${ }^{99 \mathrm{~m}} \mathrm{Tc}\left(t_{1 / 2}=2.13 \times 10^{5}\right.$ years $)$. Besilesomab is able to bind to antigenic structures shared by NCA-95 of granulocytes. Therefore, $\left[{ }^{99 \mathrm{~m}} \mathrm{Tc}\right]$ besilesomab binds to neutrophils and

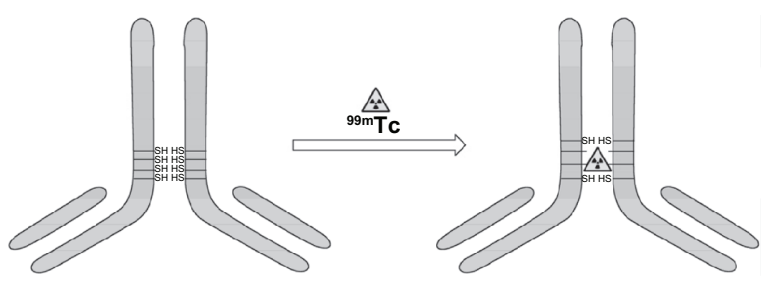

Figure 3 Radiolabeling of besilesomab. accumulates at sites of infection and inflammation. These sites appear as corresponding hotspots during scintigraphic imaging, allowing physicians to accurately and noninvasively locate and diagnose infectious and inflammatory lesions. This was a major advance in imaging osteomyelitis, reflected by the number of patients who have received $\left[{ }^{99 \mathrm{~m}} \mathrm{Tc}\right]$ besilesomab scintigraphy studies (estimated to be $>100,000$, globally).

\section{Pharmacological considerations}

Extensive pharmacological data for [ $\left.{ }^{99 \mathrm{~m}} \mathrm{Tc}\right]$ besilesomab were presented in an assessment report on the evaluation of [ $\left.{ }^{99 \mathrm{~m}} \mathrm{Tc}\right]$ besilesomab for human use by the European Medicines Agency (EMEA).$^{59}$ The applicant was CIS Bio International and key findings from the EMEA report are concisely presented here for completeness.

\section{Absorption}

The pharmacokinetic (PK) profile of besilesomab was evaluated in cynomolgus monkeys after intravenous administration of $0.5 \mathrm{mg}$ antibody $/ \mathrm{kg}$ of besilesomab with decayed ${ }^{99 \mathrm{~m}} \mathrm{Tc}$. As expected, serum levels were found to be highest $(14.5 \mu \mathrm{g} / \mathrm{mL})$ at 10 minutes postinjection $(n=2)$. Subsequently, distribution of the antibody was found to be complete within 20 minutes, and the half-life of the antibody was 31 hours $(n=2)$. In a related PK study, [ $\left.{ }^{99 \mathrm{~m}} \mathrm{Tc}\right]$ besilesomab $(2.5 \mu \mathrm{g}$ antibody and 4-5 MBq ${ }^{99 m} \mathrm{Tc}$ ) was administered intravenously to rats, and the radioactivity in blood, tissues, urine, and feces was measured at a range of time points between 1 and 48 hours after administration. At 1 hour, the highest levels of radioactivity were found in the blood, followed by the liver, kidneys, compact bone, and small intestine. Elimination from most organs was found to be biphasic (half-lives of the initial and terminal phases were $2-7$ and $<100$ hours, respectively). Plasma half-life was found to be $30-35$ hours.

\section{Distribution and dosimetry}

Clinical distribution and dosimetry data were obtained throughout a clinical trial of 24 patients with suspected inflammation (open-label, nonrandomized, parallel group design phase I study). Half of the patients received a single intravenous injection of either $0.25 \mathrm{mg}$ (492 MBq) or $1 \mathrm{mg}$ (623 MBq) of [ $\left.{ }^{99 \mathrm{~m}} \mathrm{Tc}\right]$ besilesomab. Blood and urine samples for measurement of ${ }^{99 \mathrm{~m}} \mathrm{Tc}$ radioactivity and antibody concentration were taken over 24 hours postinjection. Moreover, additional samples for determination of antibody concentration were taken up to 30 days postinjection. The concentration-time curves obtained in these measurements showed two phases: an early phase (0-2 hours) and a late 
phase (5-24 hours). Besilesomab antibody-based half-lives and clearance rates agreed with the corresponding plasma radioactivity values, suggesting that the labeled product was stable in vivo. The biodistribution data, measured in this study as percentage of regional activity vs whole body activity, showed similar results for the liver: $1.5 \%$ of whole body activity for imaging at 6 hours and 1.6\% at 24 hours. The corresponding data for the spleen were $3.0 \%$ at 6 hours and $2.3 \%$ at 24 hours.

Dosimetry was calculated using the Medical Internal Radiation Dose (MIRD) system and is summarized in Table 1. The effective dose was estimated at $8.63 \times 10^{-3} \mathrm{mSv} / \mathrm{MBq}$ of $\left[{ }^{99 \mathrm{~m}} \mathrm{Tc}\right]$ besilesomab administered to the patient. ${ }^{59}$

\section{Metabolism and excretion}

Like most antibodies, besilesomab is metabolized into amino acids during hepatic clearance. Therefore, in addition to the labeled antibody, total blood radioactivity also includes contributions from other radioactive species, such as antibody fragments, metabolites, and free ${ }^{99 \mathrm{~m}} \mathrm{Tc}$. Each of these by-products is cleared from blood differently. Although the radioactivity associated with intact antibody will stay

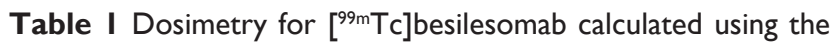
MIRD system ${ }^{59}$

\begin{tabular}{lll}
\hline Organ & $(\mathbf{m S v} / \mathbf{M B q})$ & \\
\cline { 2 - 3 } & Reference male & Reference female \\
\hline Brain & 0.00236 & 0.00312 \\
Heart & 0.00495 & 0.00597 \\
Colon & 0.00450 & 0.00576 \\
Stomach & 0.00445 & 0.00535 \\
Liver & 0.00100 & 0.00126 \\
Small intestine & 0.00480 & 0.00575 \\
Bone marrow (red) & 0.00242 & 0.00229 \\
Muscles & 0.00317 & 0.00391 \\
Ovaries & $\mathrm{NA}$ & 0.00594 \\
Pancreas & 0.00690 & 0.00826 \\
Skin & 0.00178 & 0.00216 \\
Lungs & 0.00125 & 0.00160 \\
Spleen & $0.0027 \mathrm{I}$ & 0.00324 \\
Kidney & 0.00210 & 0.00234 \\
Breast & $\mathrm{NA}$ & 0.00301 \\
Adrenal & 0.00759 & 0.00937 \\
Testis & 0.00182 & $\mathrm{NA}$ \\
Thymus & 0.00351 & 0.00423 \\
Thyroid & 0.00279 & 0.00321 \\
Bone & 0.00177 & 0.00227 \\
Uterus & $\mathrm{NA}$ & $0.0050 \mathrm{I}$ \\
Gallbladder & $0.0059 \mathrm{I}$ & $0.0068 \mathrm{I}$ \\
Bladder & 0.00305 & 0.00380 \\
Whole body & 0.00445 & 0.00552 \\
\hline Note: Ective &
\end{tabular}

Note: Effective dose, $0.00863 \mathrm{mSv} / \mathrm{MBq}$.

Abbreviations: ${ }^{99 \mathrm{~m}} \mathrm{Tc}$, technetium-99m; MIRD, Medical Internal Radiation Dose; NA, not applicable. in the blood for a reasonable time (antibody half-life in plasma $=44.5$ hours $^{59}$ ), metabolites, radioactive fragments, and free ${ }^{99 \mathrm{~m}} \mathrm{Tc}$ will clear more rapidly from blood and will accumulate in the kidneys and, ultimately, in the urine. In all studies, about $14 \%$ of the injected radioactivity was recovered in urine, which was only collected for 24 hours after administration. This radioactivity can be attributed to the elimination of free ${ }^{99 \mathrm{~m}} \mathrm{Tc}$ and labeled low-molecular-weight antibody fragments and small radiometabolites. In this report, no information about the fate of the injected radioactivity beyond 24 hours postadministration of [ $\left.{ }^{99 \mathrm{~m}} \mathrm{Tc}\right]$ besilesomab was provided. However, the radioactivity absorbed by the kidneys ( $0.022 \mathrm{mGy} / \mathrm{MBq}$ on average) lies in the range of other approved ${ }^{99 \mathrm{~m}}$ Tc-labeled radiopharmaceuticals.

\section{Safety profile}

A number of genotoxicity studies have been conducted, which conclude that $\left[{ }^{99 m} \mathrm{Tc}\right]$ besilesomab does not show genotoxic potential. ${ }^{59}$ Moreover, according to a report submitted to the EMEA, approximately 100,000 patients have received [ $\left.{ }^{99 \mathrm{~m}} \mathrm{Tc}\right]$ besilesomab to date. The radiopharmaceutical appears well tolerated, and there have been few reported side effects or adverse events. ${ }^{59}$

\section{Mechanism of action}

The mechanism of accumulation of besilesomab at the site of infection and inflammation has not been fully elucidated. However, it has been suggested that it is mainly passive (increased vascular permeability) and partly active (migration of human granulocytes, carrying [ $\left.{ }^{99 \mathrm{~m}} \mathrm{Tc}\right]$ besilesomab, to the infection and inflammation sites) because only $10 \%-20 \%$ of the injected radiolabeled antibody bind in vivo to human circulating granulocytes. Specific binding of besilesomab to already migrated and activated granulocytes may be the major part of the detection signal. ${ }^{59}$ Besilesomab binds granulocytes that express NCA-95, but it has been shown that such binding does not significantly affect granulocyte-mediated functions (eg, enzyme release and pinocytosis). ${ }^{60}$ Moreover, besilesomab does not get internalized into the cytoplasm. ${ }^{61}$

\section{Imaging inflammation and infection in patients with suspected osteomyelitis using besilesomab}

During the 15 years since the introduction of $\left[{ }^{99 \mathrm{~m}} \mathrm{Tc}\right]$ besilesomab, numerous clinical studies evaluating its effectiveness in diagnosing osteomyelitis have been reported (Table 2). ${ }^{29,34,47,59,62-73}$ These studies have also been the subject of review ${ }^{20,33,51,74,75}$ and retrospective data analysis, ${ }^{29,76}$ and 


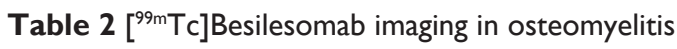

\begin{tabular}{|c|c|c|c|c|c|}
\hline Type & $\mathbf{N}$ & Dose (MBq) & Scan time (h) & Results & Reference \\
\hline Suspected peripheral osteomyelitis & 55 & $300-500$ & $2-6 ; 20-24$ & sp, $57 \%$; se, $94 \%$; ac, $65 \%$ & Ruther et $\mathrm{a}^{67}$ \\
\hline $\begin{array}{l}\text { Suspected peripheral and central } \\
\text { osteomyelitis }\end{array}$ & 57 & 740 & $4-6 ; 24$ & sp, $92 \%$; se, $88 \%$; ac, NR & Kroiss et $\mathrm{a}^{72}$ \\
\hline Suspected chronic osteomyelitis & 17 & 500 & $4 ; 24$ & sp, $100 \%$; se, $100 \%$; ac, NR & Sciuk et $\mathrm{a}^{166}$ \\
\hline $\begin{array}{l}\text { Suspected peripheral and central } \\
\text { osteomyelitis }\end{array}$ & 58 & 740 & $3-6 ; 24$ & sp, $91 \%$; se, $96 \%$; ac, $93 \%$ & Seybold et $\mathrm{al}^{68}$ \\
\hline $\begin{array}{l}\text { Suspected peripheral and central } \\
\text { osteomyelitis }\end{array}$ & 30 & 500 & $4 ; 20-24$ & sp, $64 \%$; se, $89 \%$ & Hotze et $\mathrm{a}^{62}$ \\
\hline Suspected peripheral osteomyelitis & 8 & 725 & $2 ; 24$ & sp, $75 \%$; se, $57 \%$; ac, $67 \%$ & Peltier et a $\mathrm{l}^{70}$ \\
\hline Suspected peripheral osteomyelitis & 106 & $300-400$ & $2-4$ & sp, $93 \%$; se, $69 \%$; ac, $81 \%$ & Reuland et $a^{64}$ \\
\hline $\begin{array}{l}\text { Chronic posttraumatic peripheral } \\
\text { osteomyelitis }\end{array}$ & 24 & 555 & 17 & sp, $72 \%$; se, $84 \%$; ac, $79 \%$ & Kaim et a ${ }^{65}$ \\
\hline Joint prosthesis & 57 & 750 & $0 ; 2 d-4 w$ & sp, $75 \%$; se, $67 \%$; ac, $73 \%$ & Boubaker et $\mathrm{a}^{85}$ \\
\hline $\begin{array}{l}\text { Suspected peripheral and central } \\
\text { osteomyelitis }\end{array}$ & 51 & 420 & $4 ; 24$ & $\begin{array}{l}\text { sp, } 77 \% \text { vs } 82 \% \text {; se, } 86 \% \text { vs } 92 \% \text {; } \\
\text { ac, } 82 \% \text { vs } 88 \%\end{array}$ & Guhlmann et $\mathrm{al}^{47}$ \\
\hline Suspected central osteomyelitis & 81 & $555-925$ & $\mathrm{I} ; 4 ; 24$ & sp, $96 \%$; se, $95 \%$; ac, NR & Gratz et $\mathrm{al}^{71}$ \\
\hline Suspected peripheral osteomyelitis & 10 & 740 & $4-6 ; 24$ & NR & Gallowitsch et al ${ }^{69}$ \\
\hline $\begin{array}{l}\text { Chronic posttraumatic } \\
\text { osteomyelitis }\end{array}$ & 27 & 750 & $0 ; 3-4 ; 24$ & sp, $100 \%$; se, 78\%; ac, NR\% & Horger et $\mathrm{al}^{63}$ \\
\hline $\begin{array}{l}\text { Phase I trial to determine safety, } \\
\mathrm{PK} \text {, and diagnostic efficacy }\end{array}$ & 24 & $\begin{array}{l}0.25 \mathrm{mg}^{\mathrm{a}} \\
\mathrm{I} .0 \mathrm{mg}^{\mathrm{a}}\end{array}$ & NR & $\begin{array}{l}\text { sp, } 88 \% ; \text { se, } 100 \% \\
\text { sp, } 93 \% \text {; se, } 100 \%\end{array}$ & CIS Bio International ${ }^{59}$ \\
\hline $\begin{array}{l}\text { Phase III trial in patients with } \\
\text { inflammatory diseases }\end{array}$ & 690 & $\begin{array}{l}<400 \\
400-600 \\
600-800 \\
>800\end{array}$ & $5 ; 24$ & $\begin{array}{l}\text { sp, 100\%; se, } 73.5 \% \\
\text { sp, } 94.9 \% \text {; se, } 90.1 \% \\
\text { sp, } 95.7 \% \text {; se, } 90.6 \% \\
\text { sp, } 89.7 \% \text {; se, } 88.8 \%\end{array}$ & CIS Bio International ${ }^{59}$ \\
\hline $\begin{array}{l}\text { Phase III trial in patients with } \\
\text { suspected peripheral osteomyelitis }\end{array}$ & 119 & $650-800$ & $4 ; 24$ & $\begin{array}{l}\text { sp, } 69 \% \text {; se, } 76 \% \text {; ac, NR\% } \\
\text { Scint: sp, } 60 \% \text {; se } 66 \% \\
\text { Scint + SPECT: sp, }\end{array}$ & CIS Bio International ${ }^{59}$ \\
\hline $\begin{array}{l}\text { Detection of low-grade joint } \\
\text { infections }\end{array}$ & 31 & NR & $5 \mathrm{~min} ; 5 ; 24$ & $\begin{array}{l}55 \% ; \text { se, } 89 \% \\
\text { Scint + SPECT/CT: sp, } \\
73 \% \text {; se, } 89 \%\end{array}$ & Graute et $\mathrm{a}^{34}$ \\
\hline
\end{tabular}

Notes: aDose of radioactivity was not reported but rather injected dose of antibody in $\mathrm{mg}$.

Abbreviations: sp, specificity; se, sensitivity; ac, accuracy; NR, not reported; PK, pharmacokinetic; Scint, [ ${ }^{99 m}$ Tc]besilesomab scintigraphy; SPECT, single photon emission computed tomography; CT, computed tomography.

the outcome of the body of research suggests that diagnostic accuracy of osteomyelitis using [ $\left.{ }^{99 \mathrm{~m}} \mathrm{Tc}\right]$ besilesomab is high. ${ }^{51}$ $\left[{ }^{99 \mathrm{~m}} \mathrm{Tc}\right]$ Besilesomab has also been used to detect inflammation ${ }^{77}$ and infection in other diseases, such as diabetic foot, ${ }^{78,79}$ fevers of unknown origin, ${ }^{80}$ inflammatory bowel disease, ${ }^{81-83}$ and septic loosening of $\mathrm{knee}^{84}$ or hip ${ }^{85}$ endoprosthesis, although a detailed discussion of such uses extends beyond the scope of this report. Beyond diagnosis of infection and inflammation, bone marrow scintigraphy has been used to track bone metastases in cancer patients ${ }^{86,87}$ and has also been considered for radiotherapeutic applications. ${ }^{88}$

Recently, an assessment report from the EMEA, in response to CIS Bio International's application for marketing authorization, summarizes data from eight separate clinical trials of $\left.{ }^{[99 \mathrm{~m}} \mathrm{Tc}\right]$ besilesomab. For example, a randomized crossover trial, conducted between 2006 and 2008, compared blinded reading of $\left[{ }^{99 \mathrm{~m}} \mathrm{Tc}\right]$ besilesomab and [ $\left.{ }^{99 \mathrm{~m}} \mathrm{Tc}\right] \mathrm{WBC}$ images of suspected osteomyelitis (Table 2, entry 16)..$^{59}$ In this most recent and pivotal phase III trial involving 119 patients with suspected osteomyelitis, the agreement rate between the 2 methods was estimated to be $83 \%$ (lower $95 \%$ confidence interval limit: $80 \%$ ); however, there was no adequate standard of truth (or acceptable surrogate) used in this trial, and so diagnostic parameters like sensitivity and specificity could not be calculated. The lack of standard of truth was addressed during post hoc analysis based on a surrogate, which was an evaluation by an expert panel of all data available from the study. The overall diagnostic performance of [ $\left.{ }^{99 \mathrm{~m}} \mathrm{Tc}\right]$ besilesomab determined during this post hoc analysis (sensitivity, $76 \%$; specificity, 69\%) was similar to that of the previous analysis based on the investigator diagnosis at 1 month (75\% and $72 \%$, respectively).

The data presented in Table 2 support clinical trial data from the EMEA report ${ }^{59}$ about the apparent relationship between injected dose of $\left[{ }^{99 \mathrm{~m}} \mathrm{Tc}\right]$ besilesomab and the sensitivity or specificity of the scintigraphy studies. For example, in one of CIS Bio International's clinical trials (Table 2, entry 15), retrospective data analysis factoring in dose 
administered to 690 patients confirmed that there was no statistical difference in sensitivity or specificity between the groups receiving different doses of [ $\left.{ }^{99 \mathrm{~m}} \mathrm{Tc}\right]$ besilesomab. However, lower sensitivities were observed in this trial for patients who received $<400 \mathrm{MBq}$ of [ ${ }^{99 \mathrm{~m}} \mathrm{Tc}$ ] besilesomab, and so, the optimum dose for these studies was set at 400-800 MBq. ${ }^{59}$ These data are similar to those reported by Reuland et $\mathrm{al}^{64}$ (Table 2, entry 7). Reuland et $\mathrm{al}^{64}$ injected $<400 \mathrm{MBq}$ and observed a sensitivity of $69 \%$, although it should be noted that lower sensitivities have also been observed with higher injected doses (eg, Peltier et $\mathrm{al}^{70}$ reported $57 \%$ sensitivity following injection of $725 \mathrm{MBq}$; Table 2, entry 6).

The results reported from the CIS Bio International's clinical trials are in agreement with other studies reported in the literature (Table 2). For example, in the discussion of advanced experience in diagnosing infections with scintigraphy, Seybold et $\mathrm{al}^{68}$ examined 58 patients with infection using [ ${ }^{99 \mathrm{~m}} \mathrm{Tc}$ ]besilesomab. Patients were administered $\sim 300 \mu \mathrm{g}$ of antibody, corresponding to $740 \mathrm{MBq}$ of ${ }^{99 \mathrm{~m}} \mathrm{Tc}$. In this study, it was reported that sensitivity, specificity, and accuracy were $91 \%, 96 \%$, and $93 \%$, respectively, and the authors found comparable diagnostic findings to use radiolabeled MAb47. They concluded that [ $\left.{ }^{99 \mathrm{~m}} \mathrm{Tc}\right]$ besilesomab had an overall positive predictive value of $97 \%$.

In 1997, Kaim et a ${ }^{65}$ explored the use of [ $\left.{ }^{99 \mathrm{~m}} \mathrm{Tc}\right]$ besilesomab for imaging chronic posttraumatic osteomyelitis. They compared diagnosis in 24 patients using a [ ${ }^{99 \mathrm{~m}} \mathrm{Tc}$ ]diphosphonate bone scan and MRI, with diagnosis made using the combination of $\left[{ }^{99 \mathrm{~m}} \mathrm{Tc}\right]$ diphosphonate bone scan and [ $\left.{ }^{99 \mathrm{~m}} \mathrm{Tc}\right]$ besilesomab with MRI. The addition of [ $\left.{ }^{99 \mathrm{~m}} \mathrm{Tc}\right]$ besilesomab scintigraphy greatly improved diagnostic accuracy. Sensitivity, specificity, and accuracy for the bone scan alone were $92 \%$, $18 \%$, and $58 \%$, respectively, whereas these values were $84 \%$, $72 \%$, and $79 \%$ for the combined bone scan and scintigraphy. These results confirm that [ $\left.{ }^{99 \mathrm{~m}} \mathrm{Tc}\right]$ besilesomab scintigraphy is a very sensitive, accurate, and reproducible method for evaluating chronic osteomyelitis. However, this study also supports the idea that, when imaging suspected osteomyelitis, diagnostic confidence is improved if a combination of imaging techniques is used rather than a single technique alone. This concept has also been demonstrated by Graute et $\mathrm{al}^{34}$ in an abstract presented at the 2010 Society of Nuclear Medicine Annual Meeting. In this study, 31 patients had [ $\left.{ }^{99 \mathrm{~m}} \mathrm{Tc}\right]$ besilesomab bone scintigraphy carried out at 5 minutes, 5 hours, and 24 hours after injection. Diagnostic sensitivity of the scans was assessed alone and in conjunction with SPECT and SPECT/CT (Table 2, entry 17). The use of [ ${ }^{99 m}$ Tc] besilesomab bone scintigraphy alone resulted in a specificity of $60 \%$ and sensitivity of $66 \%$. Interpreting scintigraphy in conjunction with the SPECT scan resulted in improved sensitivity, whereas specificity was found to be lower (specificity, 55\%; sensitivity, $89 \%$ ). However, marked improvement in both parameters was observed when scintigraphy data were interpreted with SPECT and CT (specificity, 73\%; sensitivity, 89\%). Similar data were reported for $\left[{ }^{99 \mathrm{~m}} \mathrm{Tc}\right]$ besilesomab by Horger et $\mathrm{al}^{63}$ in their 2003 study and for [ $\left.{ }^{99 \mathrm{~m}} \mathrm{Tc}\right]$ diphosphonate by Wuest et al. ${ }^{36,89}$

Nevertheless, there are challenges to evaluating osteomyelitis with [ ${ }^{99 \mathrm{~m}} \mathrm{Tc}$ ] besilesomab. Typically, these include false-positive and false-negative diagnoses. For example, less encouraging results were reported by Hotze et $\mathrm{al}^{62}$ in 1992 when 20 patients with suspected peripheral osteomyelitis and 10 patients with suspected infection of the spine were scanned with [ ${ }^{99 \mathrm{~m}} \mathrm{Tc}$ ] besile-

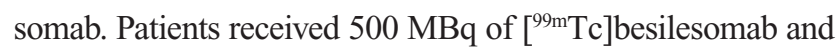
were scanned at 4 hours and 20-24 hours postinjection. In many cases, the scan was successful in revealing osteomyelitis. For example, the scan shown in Figure 4 was taken for a patient with a history of arthrodesis of the right ankle joint and subsequent chronic pain. The scan suggests infection, and indeed, in this case, chronic osteomyelitis was confirmed by biopsy.

However, of the 20 patients with suspected peripheral osteomyelitis, four false-positive and one false-negative findings were also observed, giving a specificity of $64 \%$ and sensitivity of $89 \%$. These false-positive and false-negative results support the conclusions of a number of groups that scintigraphy is a powerful tool when used in conjunction with other modern imaging modalities, such as MRI or CT, and histologic examinations. ${ }^{9,29,76}$

Finally, Guhlmann et $\mathrm{al}^{47}$ compared $\left[{ }^{99 \mathrm{~m}} \mathrm{Tc}\right]$ besilesomab antibody scintigraphy (patients were scanned 4 and 24 hours

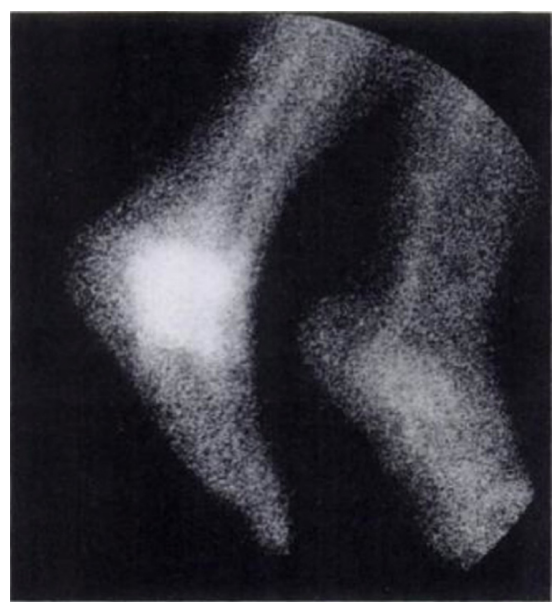

Figure 4 Image of chronic osteomyelitis obtained using $\left[{ }^{99 \mathrm{~m}} \mathrm{Tc}\right]$ besilesomab. Copyright (C) 1992, Society of Nuclear Medicine. Reprinted with permission from Hotze AL, Briele B, Overbeck B, et al. Technetium-99m-labeled anti-granulocyte antibodies in suspected bone infections. J Nucl Med. 1992;33:526-531. 


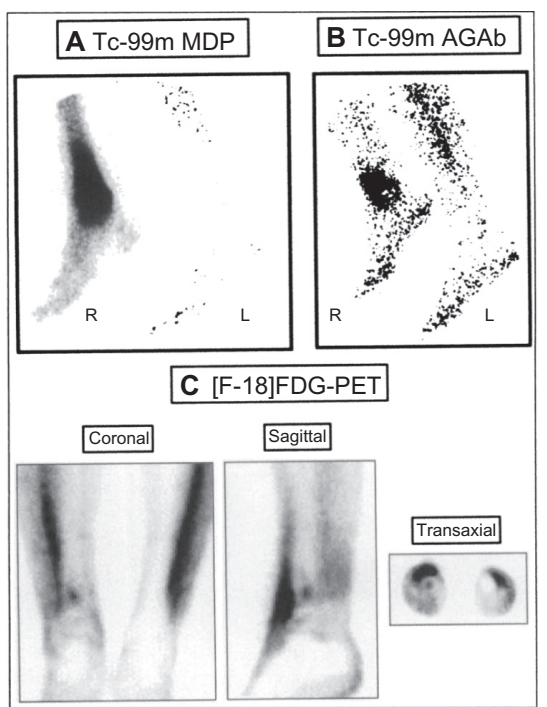

Figure 5 A comparison of $\left[{ }^{99 m} \mathrm{Tc}\right]$ besilesomab, $\left[{ }^{99 \mathrm{~m} T c] M D P}\right.$, and $\left[{ }^{18} \mathrm{~F}\right] \mathrm{FDG}-\mathrm{PET}$ imaging of osteomyelitis. Copyright (C) 1998, Society of Nuclear Medicine. Reprinted with permission from Guhlmann A, Brecht-Krauss D, Suger G, et al. Fluorine-18-FDG PET and technetium-99m Antigranulocyte Antibody Scintigraphy in Chronic Osteomyelitis. J Nucl Med. 1998;39:2145-2152.

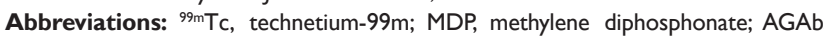
antigranulocyte antibody; R, right; L, left; [ $\left.{ }^{18} \mathrm{~F}\right] \mathrm{FDG}-\mathrm{PET}$, fluorine-18 fluorodeoxyglucose positron emission tomography.

after administration of $0.3-0.5 \mathrm{mg} / 420 \mathrm{MBq}$ of $\mathrm{MAb}$ ) with $\left[{ }^{18} \mathrm{~F}\right]$ FDG-PET imaging (patients were scanned 50 minutes after administration of $320 \mathrm{MBq}$ of $\left.\left[{ }^{18} \mathrm{~F}\right] \mathrm{FDG}\right)$ for detection of chronic osteomyelitis (Figure 5). Fifty-one patients who previously had a $\left[{ }^{99 \mathrm{~m}} \mathrm{Tc}\right] \mathrm{MDP}$ bone scan were investigated, and two expert readers analyzed the data. They concluded that although both methods were suitable for diagnosis of chronic osteomyelitis in the peripheral skeleton, FDG-PET was superior (accuracy, $96 \%$ vs $96 \%$; sensitivity, $100 \%$ vs 97\%; and specificity, $95 \%$ vs $95 \%$ ) to [ $\left.{ }^{99 \mathrm{~m}} \mathrm{Tc}\right]$ besilesomab (accuracy, $82 \%$ vs $88 \%$; sensitivity, $86 \%$ vs $92 \%$; and specificity, $77 \%$ vs $82 \%$ ). The main difference between the two imaging agents in this study was that FDG allowed more reliable distinction between osteomyelitis and infection of the surrounding soft tissue.

\section{Conclusion}

Antigranulocyte scintigraphy with radiolabeled MAbs has proven a reliable method for diagnosing osteomyelitis. One such antibody, $\left.{ }^{[9 \mathrm{~m}} \mathrm{Tc}\right]$ besilesomab, is commercially available, and over 100,000 patients have received a scan with this agent. $\left.{ }^{[99 \mathrm{~m}} \mathrm{Tc}\right]$ Besilesomab has proven effective for determining the location of inflammation and infection in peripheral bone in adults with suspected osteomyelitis. However, at the time of writing, there are currently no criteria to distinguish infection and inflammation by means of [ $\left.{ }^{99 \mathrm{~m}} \mathrm{Tc}\right]$ besilesomab imaging. The reported data suggest that the sensitivity of $\left[{ }^{99 \mathrm{~m}} \mathrm{Tc}\right.$ ] besilesomab is equivalent to that of [ ${ }^{99 \mathrm{~m}} \mathrm{Tc}$ ]WBCs but specificity is lower. A lower specificity is considered acceptable because it has been shown that diagnostic confidence can be significantly improved when $\left[{ }^{99 \mathrm{~m}} \mathrm{Tc}\right]$ besilesomab is used in conjunction with other appropriate imaging modalities, such as bone scans or SPECT/CT imaging.

\section{Acknowledgment}

Peter JH Scott gratefully acknowledges the office of Biological and Environmental Research (BER) of the office of Science (SC), US Department of Energy (DE-FG02-08ER64645) for financial support.

\section{Disclosure}

The authors report no conflicts of interest in this work.

\section{References}

1. Lew DP, Waldvogel FA. Osteomyelitis. Lancet. 2004;364:369-379.

2. Jauregui LE, Senour CL. Chronic osteomyelitis. In: Jauregui LE, editor. Diagnosis and Management of Bone Infections. New York, NY: Marcel Dekker; 1995:37-108.

3. Waldvogel FA, Papageorgiou PS. Osteomyelitis: the past decade. $N$ Engl J Med. 1980;303:360-370.

4. Calhoun J, Manring M. Adult osteomyelitis. Infect Dis Clin North Am 2005;19:765-786.

5. Kaplan S. Osteomyelitis in children. Infect Dis Clin North Am. 2005; 19:787-797.

6. Lew DP, Waldvogel FA. Osteomyelitis. N Engl J Med. 1997;336: 999-1007.

7. Esposito S, Leone S, Bassetti M, et al. Italian guidelines for the diagnosis and infectious disease management of osteomyelitis and prosthetic joint infections in adults. Infection. 2009;6:478-496.

8. Hartemann-Heurtier A, Senneville E. Diabetic foot osteomyelitis Diabetes Metab. 2008;34:87-95.

9. Prandini N, Lazzeri E, Rossi B, Erba P, Parisella MG, Signore A. Nuclear medicine imaging of bone infections. Nucl Med Commun. 2006;27:633-644.

10. Waldvogel FA, Medoff G, Swartz MN. Osteomyelitis: a review of clinical features, therapeutic considerations and unusual aspects. $N$ Engl J Med. 1970;282:316-322.

11. Cierny G, Mader JT, Pennick JJ. A clinical staging system for adult osteomyelitis. Contemp Orthop. 1985;10:17-37.

12. Ciampolini J, Harding KJ. Pathophysiology of chronic bacterial osteomyelitis. Why do antibiotics fail so often? Postgrad Med J. 2000;76: 479-483.

13. Brady RA, Leid JG, Calhoun JH, Costerton JW, Shirtliff ME. Osteomyelitis and the role of biofilms in chronic infection. FEMS Immunol Med Microbiol. 2008;52:13-22.

14. Lazzarini L, Mader JT, Calhoun JH. Osteomyelitis in long bones. J Bone Joint Surg Am. 2004;86:2305-2318.

15. Mackowiack PA, Jones SR, Smith JW. Diagnostic value of sinus-tract cultures in chronic osteomyelitis. JAMA. 1978;239:2772-2775.

16. Perry CR, Pearson RL, Miller GA. Accuracy of cultures of material from swabbing of the superficial aspect of the wound and needle biopsy in the properative assessment of osteomyelitis. J Bone Joint Surg Am. 1991;73:745-749.

17. Haas DW, McAndrew MP. Bacterial osteomyelitis in adults: evolving considerations in diagnosis and treatment. Am J Med. 1996;101: $550-561$. 
18. Mader JT, Shirtliff ME, Bergquist SC, Calhoun J. Antimicrobial treatment of chronic osteomyelitis. Clin Orthop Relat Res. 1999;360:47-65.

19. Seabold JE, Flickinger FW, Kao SCS, et al. Indium-111-leukocyte/ technetium-99m-MDP bone and magnetic resonance imaging: difficulty of diagnosing osteomyelitis in patients with neuropathic osteoarthropathy. J Nucl Med. 1990;31:549-556.

20. Signore A, Mather SJ, Piaggio G, Malviya G, Dierckx RA. Molecular imaging of inflammation/infection: nuclear medicine and optical imaging agents and methods. Chem Rev. 2010;110:3112-3145.

21. Sammak B, Bagi MAE, Shahed MA, et al. Osteomyelitis: a review of currently used imaging techniques. Eur Radiol. 1999;9:894-900.

22. Pineda C, Vargas A, Rodriguez AV. Imaging osteomyelitis: current concepts. Infect Dis Clin North Am. 2006;20:789-825.

23. Marshall D, Haskard DO. Quantifying inflammation in vivo using radiolabeled antibodies and leukocytes. In: Winyard PG, Willonghby DA, editors. Methods in Molecular Biology. Vol 225: Inflammation Protocols; 2003. p. 273-282.

24. Becker W, Goldenberg DM, Wolf F. The use of monoclonal antibodies and antibody fragments in the imaging of infectious lesions. Semin Nucl Med. 1994;24:142-153.

25. Walker RC, Jones-Jackson LB, Martin W, Habibian MR, Delbeke D. New imaging tools for the diagnosis of infection. Future Microbiol. 2007;2:527-554.

26. Albiri MM, Kirpekar M, Ablow RC. Osteomyelitis: detection with US. Radiology. 1989;172:509-514.

27. Robben SG. Ultrasonography of musculoskeletal infections in children. Eur Radiol. 2004;14 Suppl 4:L65-L77.

28. Fayad LM, Carrino JA, Fishman EK. Musculoskeletal infection: role of CT in the emergency department. Radiographics. 2007;27:1723-1736.

29. Kaim A, Ledermann HP, Bongartz G, Messmer P, Müller-Brand J, Steinbrich W. Chronic post-traumatic osteomyelitis of the lower extremity: comparison of magnetic resonance imaging and combined bone scintigraphy/immunoscintigraphy with radiolabelled monoclonal antigranulocyte antibodies. Skeletal Radiol. 2000;29:378-386.

30. Unger E, Moldofsky P, Gatenby R, Hartz W, Broder G. Diagnosis of osteomyelitis by MR imaging. Am J Roentgenol. 1988;150:605-610.

31. Fletcher BD, Scoles PV, Nelson AD. Osteomyelitis in children: detection by magnetic resonance. Radiology. 1984;150:57-60.

32. Tehranzadeh J. Magnetic resonance imaging of osteomyelitis. Crit Rev Diagn Imaging. 1992;33:495-534.

33. Locher JT. Labelled monoclonal antibodies used for detection of inflammatory processes and bone marrow metastases. Nucl Med Rev. 2001;4:129-135.

34. Graute V, Feist M, Lehner S, Bartenstein P, Hacker M. Detection of low-grade joint infections using $99 \mathrm{mTc}$-antigranulocyte SPECT/CT: initial clinical results. J Nucl Med. 2010;51 Suppl 2:1630.

35. Brugen Wvd, Bleeker-Rovers CP, Boerman OC, Gotthardt M, Oyen WJG. PET and SPECT in osteomyelitis and prosthetic bone and joint infections: a systematic review. Semin Nucl Med. 2010;40:3-15.

36. Linke R, Kuwert T, Uder M, Forst R, Wuest W. Skeletal SPECT/CT of the peripheral extremities. Am J Roentgenol. 2010;194:W329-W335.

37. Palestro CJ. In vivo leukocyte labeling: the quest continues. $J \mathrm{Nucl}$ Med. 2007;48:332-334.

38. Palestro CJ, Love C, Schneider R. The evolution of nuclear medicine and the musculoskeletal system. Radiol Clin North Am. 2009;47:505-532.

39. Gross T, Kaim AH, Regazzoni P, Widmer AF. Current concepts in posttraumatic osteomyelitis: a diagnostic challenge with new imaging options. J Trauma. 2002;52:1210-1219.

40. Love C, Tomas MB, Tronco GG, Palestro CJ. FDG PET of infection and inflammation. Radiographics. 2005;25:1357-1368.

41. Kaim AH, Gross T, Schulthess GK. Imaging of chronic posttraumatic osteomyelitis. Eur Radiol. 2002;12:1193-1202.

42. Kumar R, Basu S, Torigian D, Anand V, Zhuang H, Alavi A. Role of modern imaging techniques for diagnosis of infection in the era of 18F-fluorodeoxyglucose positron emission tomography. Clin Microbiol Rev. 2008;21:209-224.
43. Kälicke T, Schmitz J, Risse JH, et al. Fluorine-18 fluorodeoxyglucose PET in infectious bone diseases: results of histologically confirmed cases. Eur J Nucl Med. 2000;27:524-528.

44. Schmitz A, Risse HJ, Källicke T, Grünwald F, Schmitt O. FDG-PET for diagnosis and follow-up of inflammatory processes: initial results from the orthopedic viewpoint. Z Orthop Ihre Grenzgeb. 2000;138: 407-412.

45. Zhuang H, Alavi A. 18-fluorodeoxyglucose positron emission tomographic imaging in the detection and monitoring of infection and inflammation. Semin Nucl Med. 2002;32:47-59.

46. Zhuang H, Duarte PS, Pourdehand M, Shnier D, Alavi A. Exclusion of chronic osteomyelitis with F-18 fluorodeoxyglucose positron emission tomographic imaging. Clin Nucl Med. 2000;25:281-284.

47. Guhlmann A, Brecht-Krauss D, Suger G, et al. Fluorine-18-FDG PET and technetium-99m Antigranulocyte Antibody Scintigraphy in Chronic Osteomyelitis. J Nucl Med. 1998;39:2145-2152.

48. Heiba SI, Luo J, Sadek S, et al. Attenuation correction induced artifact in F-18 FDG PET imaging following total knee replacement. Clin Positron Imaging. 2000;3:237-239.

49. Zhuang H, Duarte PS, Pourdehnad M, et al. The promising role of 18F-FDG PET in detecting infected lower limb prosthesis implants. J Nucl Med. 2001;42:44-48.

50. Palestro CJ, Love C. Radionuclide imaging of musculoskeletal infection: conventional agents. Semin Musculoskelet Radiol. 2007;11:335-352.

51. Richter WS, Humplik BI. Monoclonal antibody BW 270/183 (Scintimun, Granulocyte) for scintigraphic imaging of infection/inflammation and detection of bone marrow metastases: review of the literature. Newsletter of the International Society of Radiolabeled Blood Elements. 2004;10:5-9.

52. Becker W. The contribution of nuclear medicine to the patient with infection. Eur J Nucl Med. 1995;22:1195-1211.

53. Kalin B, Axelsson B, Jacobsson H. Quantitative evaluation of four $99 \mathrm{mTc}$ colloids for bone marrow scintigraphy using single photon emission computed tomography. Nucl Med Commun. 1991; 12:135-145.

54. Flivik G, Sloth M, Rydholm U, Herrlin K, Lidgren L. Technetium99m-nanocolloid scintigraphy in orthopedic infections: a comparison with indium-111-labeled leukocytes. J Nucl Med. 1993;34: 1646-1650.

55. Papós M, Barát F, Nárai G, Dillmann J, Láng J, Csernay L. Tc-99m HMPAO leukocyte and Tc-99m nanocolloid scintigraphy in posttraumatic bone infection. Clin Nucl Med. 1998;23:423-428.

56. Ang ES, Sundram FX, Goh ASW, Aw SE. 99mTc-polyclonal IgG and 99mTc nanocolloid scans in orthopaedics: a comparison with conventional bone scan. Nucl Med Commun. 1993;14:419-432.

57. Ooi GC, Belton I, Finlay D. Comparison of technetium $99 \mathrm{~m}$ nanocolloid and indium 111 leucocytes in the diagnosis of orthopaedic infections. Br J Radiol. 1993;66:1025-1030.

58. Dutton JAE, Bird NJ, Skehan SJ, Peters AM. Evaluation of a 3-hour indium 111 leukocyte image as a surrogate for a technetium-99m nanocolloid marrow scan in the diagnosis of orthopedic infection. Clin Nucl Med. 2004;29:469-474.

59. European Medicines Agency. Assessment report for Scintimun (International Nonproprietary Name: besilesomab). 2009;Doc. Ref. EMEA/743339/2009:Procedure No. EMEA/H/C/001045.

60. Joseph K, Höffken H, Bosslet K, Schorlemmer U. In vivo labelling of granulocytes with Tc-99m-anti-NCA monoclonal antibodies for imaging inflammation. Eur J Nucl Med. 1988;14:367-373.

61. Bosslet K, Steinsträesser A, Schwarz A. Generation and functional characteristics of the granulocyte selective monoclonal antibody BW250/183. Nukl Med. 1989;28:148-159.

62. Hotze AL, Briele B, Overbeck B, et al. Technetium-99m-labeled anti-granulocyte antibodies in suspected bone infections. J Nucl Med. 1992;33:526-531.

63. Horger M, Eschmann SM, Pfannenberg C, et al. The value of SPET/ CT in chronic osteomyelitis. Eur J Nucl Med Mol Imaging. 2003;30: $1665-1673$. 
64. Reuland P, Winker KH, Heuchert T, et al. Detection of infection in postoperative orthopedic patients wiith technetium-99m-labeled monoclonal antibodies against granulocytes. J Nucl Med. 1991;32: 2209-2214.

65. Kaim A, Maurer T, Ochsner P, Jundt G, Kirsch E, Mueller-Brand J. Chronic complicated osteomyelitis of the appendicular skeleton: diagnosis with technetium-99m labelled monoclonal antigranulocyte antibody-immunoscintigraphy. Eur J Nucl Med. 1997;24:732-738.

66. Sciuk J, Brandau W, Vollet B, et al. Comparison of technetium 99m polyclonal human immunoglobulin and technetium $99 \mathrm{~m}$ monoclonal antibodies for imaging chronic osteomyelitis. Eur J Nucl Med. 1991;18:401-407.

67. Rüther W, Hotze A, Möller F, Bockisch A, Heitzmann P, Biersack HJ. Diagnosis of bone and joint infection by leucocyte scintigraphy. A comparative study with 99mTc-HMPAO-labelled leucocytes, 99mTclabelled antigranulocyte antibodies and $99 \mathrm{mTc}$-labelled nanocolloid. Arch Othop Trauma surg. 1990;110:26-32.

68. Seybold K, Frey LD, Locher J. Immunoscintigraphy of infections using 123I and 99mTc-labeled monoclonal antibodies. Advanced experiences in 230 patients. Angiology. 1992;43:85-90.

69. Gallowitsch HJ, Heinisch M, Mikosch P, et al. Tc-99m ciprofloxacin in clinically selected patients suspected for peripheral osteomyelitis, spondylodiscitis and fever of unknown origin: preliminary results. Nuklearmedizin. 2002;41:30-36.

70. Peltier P, Potel G, Lovat E, Baron D, Chatal JF. Detection of lung and bone infection with antigranulocyte monoclonal antibody BW 250/183 radiolabelled with 99Tcm. Nucl Med Commun. 1993;14:766-774.

71. Gratz S, Behr T, Herrmann A, et al. Intraindividual comparison of 99mTc-labelled anti-SSEA-1 antigranulocyte antibody and 99mTcHMPAO labelled white blood cells for the imaging of infection. Eur J Nucl Med. 1998;25:386-393.

72. Kroiss A, Böck F, Perneczky G, et al. Immunszintigraphie zur aufdeckung von Entündungsherden bei knochen- und gelenkserkrankungen. Wien Klin Wochenschr. 1990;102:713-717.

73. Gratz S, Höffken H, Kaiser JW, behr TM, Strosche H, Reize P. Nuklearmedizinische diagnostik bei schmerzhafter knieprothese. Der Radiologe. 2009;49:59-67.

74. Bleeker-Rovers CP, Vos FJ, Corstens FHM. Scintigraphic detection of infection and inflammation. In: Biersack HJ, Freeman LM, editors. Clinical Nuclear Medicine. Berlin, Germany: Springer; 2007:347-359.

75. Palestro CJ. Radionuclide imaging of infection: what the future holds. Braz Archiv Biol Technol 2008;51 (spe):1-5.

76. Pakos EE, Koumoulis HD, Fotopoulos AD, Loannidis JPA. Osteomyelitis antigranulocyte scintigraphy with $99 \mathrm{mTc}$ radiolabeled monoclonal antibodies for diagnosis: meta analysis. Radiology. 2007;245: $732-741$.
77. Lind P, Langsteger W, Költringer P, Dimai HP, Passl R, Eber O. Immunoscintigraphy of inflammatory processes with a technetium- $99 \mathrm{~m}$-labeled monoclonal antigranulocyte antibody (MAb BW 250/183). J Nucl Med. 1990;31:417-423.

78. Dominguez-Gadea L, Martin-Curto LM, de la Calle H, Crespo A. Diabetic foot infections: scintigraphic evaluation with $99 \mathrm{mTc}$-labeled anti-granulocyte antibodies. Nucl Med Commun. 1993;14:212-218.

79. Schwegler B, Stumpe KDM, Weishaupt D, et al. Unsuspected osteomyelitis is frequent in persistent diabetic foot ulcer and better diagnosed by MRI than by 18 F-FDG PET or $99 \mathrm{mTc}-\mathrm{MOAB}$. $J$ Int Med. 2007; 263:99-106

80. Becker W, Dölkemeyer U, Gramatzki M, Schneider MU, Scheele J, Wolf F. Use of immunoscintigraphy in the diagnosis of fever of unknown origin. Eur J Nucl Med. 1993;20:1078-1083.

81. Segarra I, Roca M, Baliellas C, et al. Granulocyte-specific monoclonal antibody technetium-99m-BW 250/183 and indium-111 oxine-labelled leucocyte scintigraphy in inflammatory bowel disease. Eur J Nucl Med. 1991;18:715-719.

82. Mahida YR, Perkins AC, Frier M, Wastie ML, Hawkey CJ. Monoclonal antigranulocyte antibody imaging in inflammatory bowel disease: a preliminary report. Nucl Med Commun. 1992;13:330-335.

83. Stathaki MI, Koukouraki SI, Karkavitsas NS, Koutroubakis IE. Role of scintigraphy in inflammatory bowel diseaase. World J Gastroenterol. 2009;15:2693-2700

84. Klett R, Kordelle J, Stahl U, et al. Immunoscintigraphy of septic loosening of knee endoprosthesis: a retrospective evaluation of the antigranulocyte antibody BW 250/183. Eur J Nucl Med Mol Imaging. 2003;30:1463-1466.

85. Boubaker A, Delaloye AB, Blanc CH, Dutoit M, Leyvraz PF, Delaloye B. Immunoscintigraphy with antigranulocyte monoclonal antibodies for the diagnosis of septic loosening of hip prostheses. Eur J Nucl Med. 1995;22:139-1347.

86. Duncker CM, Carrió I, Berná L, et al. Radioimmune imaging of bone marrow in patients with suspected bone metastases from primary breast cancer. J Nucl Med. 1990;31:1450-1455.

87. Sohn SK, Ahn BC, Lee SW, et al. Bone marrow immunoscintigraphy using technetium-99m anti-granulocyte antibody in multiple myeloma. Eur J Nucl Med. 2002;29:591-596.

88. Buchmann I, Kull T, Glatting G, et al. A comparison of the biodistribution and biokinetics of (99m)Tc-anti-CD66 mAb BW 250/183 and $(99 \mathrm{~m}) \mathrm{Tc}$-anti-CD45 $\mathrm{mAb}$ YTH 24.5 with regard to suitability for myeloablative radioimmunotherapy. Eur J Nucl Med Mol Imaging 2003;30:667-673.

89. Wuest W, Kuwert T, Grunewald M, et al. Skeletal SPECT/CT of the peripheral extremities: interdisciplinary approach in orthopaedic disorders - first clinical results. Cent Eur J Med. 2007;2:499-510.
Reports in Medical Imaging

\section{Publish your work in this journal}

Reports in Medical Imaging is an international, peer-reviewed, open access journal publishing original research, reports, reviews and commentaries on all areas of medical imaging. The manuscript management system is completely online and includes a very quick and fair peer-review system, which is all easy to use.

\section{Dovepress}

Visit http://www.dovepress.com/testimonials.php to read real quotes from published authors. 